\title{
CULTURAL DIFFERENCES IN PROJECT MANAGEMENT
}

\author{
Ranf Diana Elena ${ }^{l}$
}

\begin{abstract}
In tough economic times and under global competition, management by projects is now regarded as a competitive way for managing organizations. This paper wants to outline the importance of cultural differences aspects in project management. The main objectives followed by the paper are to see the impact of cultural differences of project management, to find the advantages of a multicultural team and how can we use them to face the challenges of operating in a dynamic business environment characterized by high levels of uncertainty.
\end{abstract}

Keywords: cultural, management, project, tool.

JEL codes: $M 16$

\section{Introduction}

Projects today have dramatically increased in complexity, requiring a culturally and functionally diverse mix of individuals who must be integrated into an effective unit - a project team. Effective teamwork is the key to project success during all phases of the project life cycle. Tough global competition has created an acute need for faster, more flexible, and highly competitive operations. These needs can be met only by developing high-performing teams. Effective team building is one of the prime responsibilities of the project manager (Knutson, Joan, 2001).

With the advent of the global economy comes an increased interaction between people of different countries and an increase in the need to deal with cultural differences.

Every organization has a culture unique to itself, and this is true of divisions within large corporations. The important thing to understand about culture is that in most cases there in nothing absolutely right or wrong about cultures - they just are. It is only in a relative sense that you can say something is wrong in another culture (Lewis, P. James, 2008).

Differences in national culture influence not only the surface behavior but there are also essential conditions for understanding the values adopted by business people. Each person comes to the negotiation table with skills and habits that are often not aware and that there are only subconsciously. For example there are two extreme types of behavior between Latin and Anglo Saxon, the first are followers of speech, and others are likely to listen, Latinos tend to generalize, while Anglo Saxons are very analytical, Latinos have a great spontaneity while Anglo Saxons show a remarkable self-control. But this does not mean we can not find an analytical Latin or Anglo Saxon with spontaneity. But cultures, values, beliefs and social usages cause a special style of communication for an individual or group of individuals (Zait, N., 2002).

\section{The advantages of a multicultural team}

Global project managers can use originality to deviate from general norms and obtain competitive advantage, improving the likelihood of project success. An interesting concept from recent research is crossvergence, which is "all about fusing together management practices of two or more cultures, so that a practice relevant to a heterogeneous culture can be assembled". Global teams can provide all elements for an effective fusion of different project management practices: people from various country and company cultures, enriched by different experiences and management theories,

\footnotetext{
${ }^{1}$ Romanian-German University, Sibiu, Calea Dumbrăvii no. 28-32, tel. 0269233 568, e-mail: rectorat@ roger-univ.ro
} 
implemented by a team in different countries, with a wealthy mix of skills and beliefs (Binder, Jean Carlo, 2007, p. 40-42).

Hybridization is another concept on multicultural management, which can be defined as the use of a common body of knowledge, enhanced with selective parts of successful practices from the countries where the project is being implemented, or from the team members' original culture.

You will also find different behaviors when working with a team of people from the same country, as the values and norms from the cultural dimensions are not only dependent on the nationality of team members. In our life, we can be part of different cultural groups, cumulating experiences that help make us unique. Some examples of characteristics that define our cultural groups can be:

- the region (inside the country);

- the ethnic origin;

- the religion;

- the language;

- the gender

- the age or generation;

- the education level;

- the industry you work in;

- the company;

- the job function.

When starting a global project in a new country, or when new project team members have a cultural origin that you never experienced before, the cultural dimensions can be a first source of reference to understand their general mindset, and the cultural patterns likely to be found in their culture. A second step is to read different sources of information on the country, not only to show the team members that you care for their culture, but to really understand how they live, think, and what the main sources of cultural and economic richness are. The third step and the most important is to pay attention to the behavior of the team members, to understand their values during informal conversations and to show respect for these values, while letting them know your own opinion, the project communication standards and the important norms that must be followed for them to be accepted by the other team members.

The development of these skills is not a simple task, and can only be achieved after some years of experience in multicultural teams. To reduce the time to master these skills, and improve the likelihood of success in a first global project, you can attend "soft-skills" training sessions and request coaching from more experienced global project managers. Fisher and Fisher suggest that a good training plan will also include language lessons (for people in frequent contact with a foreign language), technical training (when there are different levels of understanding on technical disciplines that can create conflicts or risks to the collaboration) and cross-cultural training (when team members and key stakeholders come from different cultural backgrounds and there are many differences in the cultural dimensions).

There are four steps framework for effective cross-cultural project management:

- Learn the definition and different types of culture - the cultural differences exist across countries but are also influenced by a diversity of age, gender, regions, religions and many other types of social groups.

- Understanding the cultural differences - use the cultural dimensions to know what differences to expect between people from different cultures. Employ a team building exercise to identify how your team and colleagues view these differences.

- Respect the cultural differences - keep the differences in mind when confronted with opposite views of the world. You must accept them and show respect for the different standpoints.

- Enjoy the richness of a multi-cultural team. Remember that you can build on the differences to identify and mitigate risks, to find alternative approaches and achieve the project objectives in better ways, and to increase the level of innovation and quality of your project deliverables. 


\section{The impact of cultural differences in project management}

It is helpful if the project team members can meet each other face to face even one time. While this can be very expensive, it may be much less expensive than not performing well on the project. Sometimes, the core project team is assembled to write and approve the project charter. The core team members would then know each other and would be inclined to give each other the benefit of doubt if there is a misunderstanding. Another method that is frequently used is to confirm meetings and calls with quick meeting minutes or e-mail follow-ups. By documenting decisions, it is easier to remember what happened and to uncover lessons learned when the project is complete (Kloppenborg, J. Timothy, 2009,

p. 118).

While abundant differences occur between people from various countries, the method and timing of project communications are of interest here. For example, Mueller and Turner studied how cultural differences impact preferred modes of project management communication. They examined how collectivism versus individualism, along with the extent individuals in various cultures accept unequal power and ambiguity, impact project communication preferences. The result show that country preferences can be shown in four categories with common preferences on frequency and type of communications for each group as shown in next figure.

\begin{tabular}{|l|l|}
\hline \multicolumn{1}{|c|}{ Country Group } & \multicolumn{1}{c|}{ Preferences } \\
\hline 1. Japan, Taiwan and Brazil & 1. Face-to-face, analytical at milestones \\
\hline 2. Hungary and India & 2. Written status reports, fixed intervals \\
\hline 3. The Netherlands and Germany & 3. Detailed progress reports, fixed intervals \\
\hline $\begin{array}{l}\text { 4. Australia, United States, Canada, New } \\
\text { Zealand, United Kingdom and Sweden }\end{array}$ & $\begin{array}{l}\text { 4. Continuous phone updates with written } \\
\text { backup }\end{array}$ \\
\hline
\end{tabular}

Fig.no. 1 - Countries and Project Communication Preferences

Source: Ralf Mueller and Rodney Turner, "Cultural Differences in Project Owner-Project Manager Communications”, Innovations Project Management Research 2004

Dean Martin identified the following seven major elements of culture, which significantly influence the project management strategy and team development process:

1. Material culture (refers to physical objects or the results of technology).

2. Language (helps develop better understanding among team members).

3. Aesthetics (encourages informal and open communication).

4. Education (indicates how different team members view the problems).

5. Religion, beliefs and attitudes (affect general attitudes toward work ethics).

6. Social organization (helps in networking and setting informal meetings).

7. Political life (relates to approvals of permits, labor laws, import/export and financial transactions).

Historically, project management was a face to face environment where tea meetings involved all players convening together in one room. The team itself may even be co-located. Today, because of the size and complexity of projects, it is impossible to find all team members located under one roof. So, we are talking about virtual project team.

The importance of culture cannot be understated. There are four important points to remember concerning the impact of culture on virtual teams identified by Duarte and Snyder. The four points are (Kerzner, Harold, 2009, p. 354):

1. There are national cultures, organizational cultures, functional cultures, and team cultures. They can be sources of competitive advantages for virtual teams that know how to use cultural differences to create synergy. Team leaders and members who understand 
and are sensitive to cultural differences can create more robust outcomes than can members of homogeneous teams with members who think and act alike. Cultural differences can create distinctive advantages for teams if they are understood and used in positive ways.

2. The most important aspect of understanding and working with cultural differences is to create a team culture in which problems can be surfaced and differences can be discussed in a productive, respectful manner.

3. It is essential to distinguish between problems that result from cultural differences and problems that are performance based.

4. Business practices and business ethics vary in different parts of the world. Virtual teams need to clearly articulate approaches to these that every member understands and abides by.

\section{The cultural gap tool}

The culture framework helps us to understand culturally diverse project stakeholders better. Yet, they are not tailored to the context of project management. Kathrin Köster have selected the most relevant culture dimensions with regard to project management and summarized them in the so-called cultural gap tool. Those are dimensions derived from business practice. Being bi-polar, the culture gap tool also simplifies cultures and is not suited to describe and analyses the behavior of a single stakeholder. Used properly, it instead highlights the biggest cultural differences between major stakeholders such as the project manager, the customer and the project team. It also relates cultural differences to the main areas of project management, sensitizing the project manager to potential differences in the behavior of stakeholders in a project management context. Knowing about those potential differences, the project manager can plan for them.

The purpose of the cultural gap tool is to raise awareness of the project manager regarding the manifestation of cultural differences in his or her project. It also can be used by the project management team and project members to help them in identifying differences and dealing with them.

The next figure indicates where in international project management the cultural differences manifest themselves. The list of bi-polar cultural dimensions with their relevance to project management areas is the so-called culture gap analysis or culture gap tool.

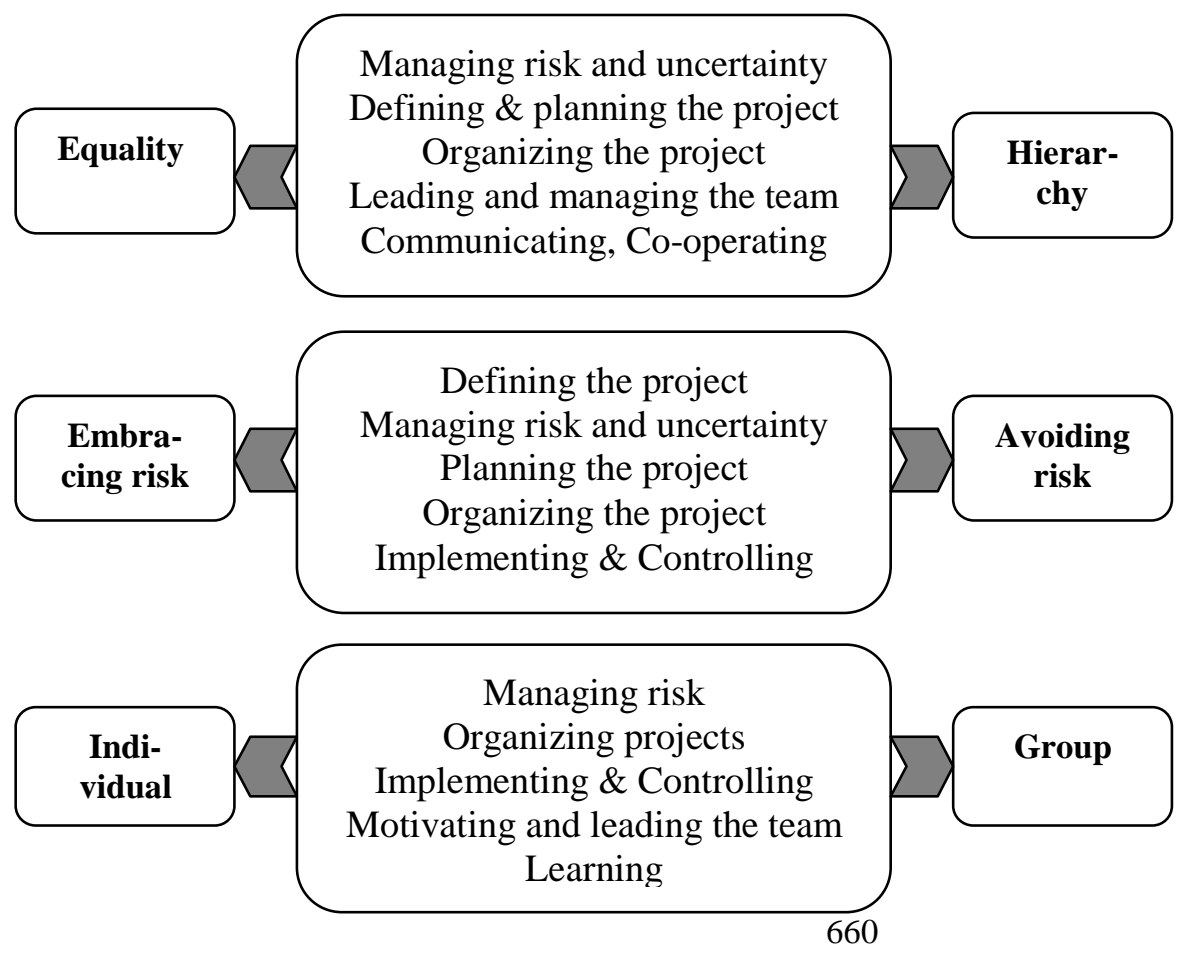




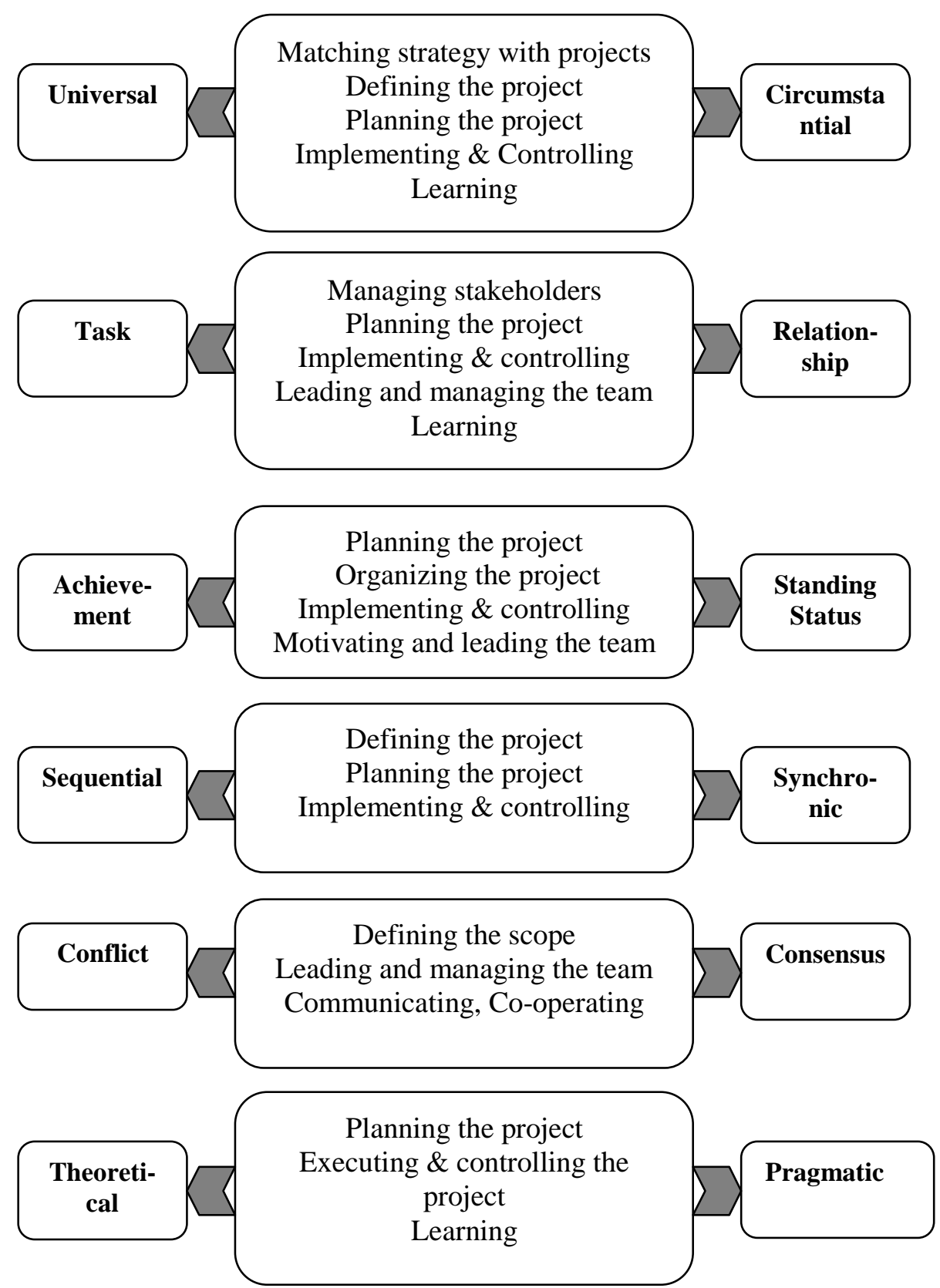

Fig.no. 2 - Culture gap tool

Source: Koster, Kathrin, 2010, p. 89-90

Of course, measuring culture exactly is not possible. The gap analysis always contains subjective elements rather than quantifiable, neutrally measurable evaluations.

Therefore, the tool serves as a proxy to become sensitized towards cultural differences. How big is the culture gap between myself as the project manager, for instance, and my customer? This is also called "cultural distance".

The gap analysis provides the management team of the international project with valuable input for the stakeholder management process. It highlights any areas of potential issues between participating stakeholders, based on the assumption that big differences or large "cultural distance", if not managed well, will lead to misunderstandings, conflict, and ultimately to project failure. 


\section{Conclusions}

With globalization comes an increased interaction between people of different countries and an increase in the need to deal with cultural differences. A project manager needs to understand his or her own culture and the cultures of the project stakeholders.

The key to success in international business is the sincere desire to integrate into a new and different culture.

Being part of a multicultural team has a lot of advantages like accumulating a lot of skills, beliefs and experiences that help make us unique.

The culture gap tool highlights the biggest cultural differences between major stakeholders such as the project manager, the customer and the project team. The purpose of the cultural gap tool is to raise awareness of the project manager regarding the manifestation of cultural differences in his or her project.

\section{References}

1. Binder, Jean Carlo, 2007. Global project management: communication, collaboration and management across borders, Gower Publishing, Hampshire, England, p. 40-42;

2. Kerzner, Harold, 2009. Project Management: a System Approach to Planning, Scheduling and Controlling, John Wiley \& Sons Publisher, New Jersey, p. 354;

3. Koster, Kathrin, 2010. International Project Management, SAGE Publication Ltd, London, p. 89-90;

4. Kloppenborg, J. Timothy, 2009. Contemporary Project Management, South Western Cengage Learning, USA, p. 118;

5. Knutson, Joan, 2001. Project management for business professionals: a comprehensive guide, John Wiley \& Sons Publisher, New York;

6. Lewis, P. James, 2008. Mastering Project Management: Applying Advanced Concepts to System Thinking, McGraw-Hill Publishing, New York.

7. Zait, N. 2002. Intercultural Management: valuing cultural differences, Economic Publisher, Bucuresti. 